\title{
MARTínez, Rosaura; VÁzQUEZ, Homero; HeRnández, Mariana (Coords.). (2018). Pensar Ayotzinapa. Almadía.
}

\author{
ÁNGELES ERAÑA LAGOS
}

Abel García Hernández, Abelardo Vázquez Periten, Adán Abrajan de la Cruz, Alexander Mora Venancio, Antonio Santana Maestro, Benjamin Ascencio Bautista, Carlos Iván Ramírez Villareal, Carlos Lorenzo Hernández Muñoz, César Manuel González Hernández, Christian Alfonso Rodríguez Telumbre, Christian Tomás Colón Garnica, Cutberto Ortíz Ramos, Dorian González Parral, Emiliano Alen Gaspar de la Cruz, Everardo Rodríguez Bello, Felipe Arnulfo Rosas, Giovanni Galindes Guerrero, Israel Caballero Sánchez, Israel Jacinto Lugardo, Jesús Jovany Rodríguez Tlatempa, Jonás Trujillo González, Jorge Álvarez Nava, Jorge Aníbal Cruz Mendoza, Jorge Antonio Tizapa Legideño, Jorge Luis González Parral, José Ángel Campos Cantor, José Ángel Navarrete González, José Eduardo Bartolo Tlatempa, José Luis Luna Torres, Jhosivani Guerrero de la Cruz, Julio César López Patolzin, Julio César Ramírez Nava, Leonel Castro Abarca, Luis Ángel Abarca Carrillo, Luis Ángel Francisco Arzola, Magdaleno Rubén Lauro Villegas, Marcial Pablo Baranda, Marco Antonio Gómez Molina, Martín Getsemany Sánchez García, Mauricio Ortega Valerio, Miguel Ángel Hernández Martínez, Miguel Ángel Mendoza Zacarías, Saúl Bruno García

¡iP R E S E N T E S!!

¡Vivos se los llevaron, vivos los queremos!

Contarlos a todos.

Nombrarlos a todos para decir: este cuerpo podría ser el mío. El cuerpo de uno de los míos.

Para no olvidar que todos los cuerpos sin nombre son nuestros cuerpos perdidos. 
Pensar Ayotzinapa se llama el libro que coordinan Rosaura Martínez, Mariana Hernández y Homero Vázquez, y es el título que hoy nos convoca a seguir pensando Ayotzinapa, a seguirlo diciendo, a no olvidar. El volumen se publicó en septiembre de 2018, cuatro años después de la noche del 26 de septiembre de 2014, día en el que asesinaron a seis personas y desaparecieron a nuestros 43 estudiantes normalistas; más de tres años después de que el Gobierno de México diera a conocer lo que ellos mismos llamaron la "verdad histórica" del caso con la que buscaban desaparecer a los desaparecidos, dándolos por muertos; meses después, casi un año, de que distintas dependencias documentaron y mostraron la falsedad de la versión oficial de los hechos. Y es que, como dice Sara Uribe (2012), "ellos dicen que sin cuerpo no hay delito [pero] sin cuerpo no hay remanso, no hay paz posible para este corazón. Para ninguno" (26). Hoy lo así ocurrido sigue sin explicación coherente, la justicia sigue sin hacerse presente, la verdad sin aparecer y el duelo sigue sin ser posible. Estas cuestiones y muchas otras que se ofrecen en los nueve textos que componen Pensar Ayotzinapa son las razones que lo hacen no sólo pertinente, sino también urgente.

Muchas de nosotras hemos cavilado reiteradamente en torno a estos hechos y sus consecuencias políticas, sociales y éticas. Se han escrito un inmenso número de artículos periodísticos y académicos al respecto. Este libro, sin embargo, tiene una peculiaridad: se acerca al suceso desde "las fronteras del psicoanálisis y la filosofía política" (Martínez, Hernández y Vázquez, 2018: 8). La mayoría de los artículos parten de una mirada analítica de la sociedad; casi todos ellos observan en esta fecha nefasta una ventana que nos ha permitido asomarnos a problemas estructurales, que nos ha hecho ver que el miedo se entreteje en nuestra realidad actual, que se nos cuela por la piel, que se inserta en nuestro ser y nos hace éstas que hoy somos y que es necesario dejar de ser para que las condiciones que lo hacen posible dejen de existir.

Los conceptos que recorren estas páginas dejan en claro que la filosofía puede (y debería siempre) ser puesta al servicio de la sociedad. Las nociones de rebeldía, resistencia, memoria, justicia, verdad - por mencionar algunas de las que están aquí repetidamente presentes - nos ayudan a mirarnos en el contexto de miedo que acabo de mencionar y al que casi todos los textos hacen referencia. Estos conceptos nos impelen a formular preguntas que contribuyan a comprender nuestra realidad y transformarla. Entre éstas se encuentran: ¿Por qué es necesaria la verdad? ¿Quiénes la construyen y cómo lo hacen? ¿Cuál es la relación entre la verdad y la justicia? ¿Cuál es la relación entre la 
memoria y la justicia? El libro también nos invita a pensar en algunas de las consignas que se han articulado como parte de la protesta posterior a aquellos hechos: “¡Fue el Estado!”, “¡Todos somos Ayotzinapa!”, “iVivos se los llevaron, vivos los queremos!". ¿Qué significan cada uno de estos gritos? Estas consignas son gritos que resuenan todavía hoy en muchos rincones de nuestro país. La primera de ellas, como dice Zenia Yébenes en la introducción del libro, nos permite recordar que aquí

"Hay una distribución diferencial del poder que impele a buscar responsabilidades diferenciadas y concretas", pero que "el Estado articula nuestra realidad como sujetos, produce y se enraíza en nuestras prácticas y discursos. Ello implica [...] reconocer que las condiciones de posibilidad que producen las desapariciones forzadas y los actos de violencia se imbrican en nuestra realidad sociocultural cotidiana". (Martínez, Hernández y Vázquez, 2018: 17-18)

La segunda - la que dice “iTodos somos Ayotzinapa!” - nos hace pensar que la desaparición de los normalistas es muestra de un fenómeno que se repite y que ocurre de manera cada vez más generalizada en nuestra sociedad. Como dice Juan José Abud Jaso, "es el único universal posible en nuestro país, ya que nombra no solamente la masacre de Iguala, sino los feminicidios, la desigualdad, el hambre, la falta de oportunidades, todas las injusticias que suceden por el hecho de haber nacido entre el Río Bravo y el Suchiate" (Martínez, Hernández y Vázquez, 2018: 92). La última consigna -la que dice “¡Vivos se los llevaron, vivos los queremos!" - no es un aullido nuevo; es una exigencia y una acción; es una esperanza que se articula en la búsqueda incansable y articula una demanda irrenunciable: que aparezcan tal como se fueron.

Los conceptos antes mencionados, por otro lado, se van articulando en los distintos textos y nos dan un panorama amplio de todo lo que tenemos pendiente por pensar y hacer no sólo en torno a Ayotzinapa y la noche de Iguala, sino también en relación con su entorno y nuestra realidad inmediata. Cuitláhuac Moreno pone especial énfasis en la noción de rebeldía. Él nos explica cómo los estudiantes normalistas vienen de una tradición rebelde $\mathrm{y}$, por lo tanto, que en este país "hacemos desaparecer la rebeldía" (Martínez, Hernández y Vázquez, 2018: 27). Las consecuencias de lo anterior son nefastas para nuestra realidad nacional, en tanto que son las rebeldías las que articulan las voces críticas que hacen posible un mundo mejor; ante todo, la rebeldía es la 
rabia organizada que articula modos nuevos de relacionarnos y mirarnos unas a las otras.

Greta Rivara nos lleva a pensar en la memoria. Revisa algunas ideas de Ricœur para examinar el vínculo entre el testimonio, la memoria, la historia y la justicia. En su texto se puede leer una exigencia clara: sin memoria no hay justicia. Desde mi perspectiva, esto puede entenderse de la siguiente manera: la justicia no tiene que ver sólo con el castigo a los culpables, sino también con escuchar las múltiples voces que hacen un acontecimiento, con dar su lugar preciso a los varios testimonios, con entender la genealogía de los sucesos para comprenderlos de manera cabal. Griselda Gutiérrez nos invita a pensar en la violencia del poder, pero sobre todo en el poder de la violencia. Este poder ha terminado por degradar a las víctimas, además de prolongarse en el tiempo y hacer imposible un proceso de duelo. La construcción de nuestras identidades constituye el núcleo de reflexión de Mariflor Aguilar, quien dice que el mensaje que la impunidad nos deja como legado es que "vale más no buscar la verdad si se quiere vivir en paz" (Martínez, Hernández y Vázquez, 2018: 149). Este mensaje nos inculca el miedo que más allá de paralizarnos nos vuelve entes aislados, islas. El problema es que sin colectividad seguiremos siendo presas del abuso. Nuestra identidad social requiere una imagen de nosotras mismas como seres libres, y para serlo necesitamos perder el miedo.

El dolor, el duelo y la melancolía son los conceptos sobre los que versan los textos de Laura Echavarría y Rosaura Martínez, quienes bordando en torno a la diferencia entre ellos hacen ver la importancia de que los familiares y todos quienes sentimos la pérdida como propia podemos elaborarla. De otro modo, nuestros desaparecidos seguirán siendo, como dice Sara Uribe (2012), "lo que deshabita desde la memoria. Tropel. Estampida. Inmersión. Diáspora. Un agujero en el bolsillo. Un fantasma que se niega a abandonarte. Nosotros somos esa invasión. Un cuerpo hecho de murmullos. Un cuerpo que no aparece, que nadie quiere nombrar. Aquí todos somos limbo" (75). Mariana Hernández nos lleva a preguntarnos por el valor de la vida y a examinar críticamente la idea de que pueda medirse, cuantificarse. Esta manera de mirar hace que algunas, algunos, sean sobrantes y, por tanto, dispensables, desaparecibles. Son los nadie a los que nadie ve, los que de por sí están ya desaparecidos. Esta manera de mirar nos cosifica y hace posible la violencia extrema que hoy vivimos. Desde su perspectiva, el mensaje que nos deja el actuar de las autoridades y del Estado en estos sucesos es que si alguien "no 
tiene valor de cambio, entonces no tiene ningún valor en sí: puede desaparecer porque no es útil ni productivo ante la racionalidad mercantil" (Martínez, Hernández y Vázquez, 2018: 145). Esta lógica está también inserta en las universidades y nos toca directamente a cada una de nosotras. Es urgente y necesario reconocer esto y "recuperar la dimensión de la subjetividad no objetivada" (Martínez, Hernández y Vázquez, 2018: 146).

Homero Vázquez examina la relación entre información y justicia. Hace ver cómo el caso Ayotzinapa ilustra las consecuencias de una ruptura en esa relación. Parte de su argumento se sostiene sobre un hecho contundente: "la PGR no buscó constatar la realidad de los hechos con las averiguaciones encontradas, sino [...] crear la realidad a partir del relato jurídico" (Martínez, Hernández, Vázquez y 2018: 165). Al hacer esto, la PGR se alejó de la posibilidad de ejercer justicia, pues sin verdad, ella no existe. Por ello, Rosaura Martínez insiste en que "la verdad es imprescindible e irremplazable" (Martínez, Hernández y Vázquez, 2018: 178), y que sólo si la conocemos podremos abrir nuevos y mejores horizontes de futuro para ellos, pero también para nosotras.

Ayotzinapa nos llevó a encontrarnos en el dolor de otros. Este libro nos invita a encontrarnos en la reflexión en torno a ese dolor; nos convida a usar nuestra herramienta de trabajo para transformar la realidad. Este libro, dice Rosaura Martínez, es un ejercicio de escritura en el que se articulan múltiples reflexiones "sobre la violencia, la vulnerabilidad y la resistencia necesaria para oponerse a grados aniquiladores de agresión" (Martínez, Hernández y Vázquez, 2018: 197). Pensar Ayotzinapa nos invita a no olvidar, a honrar a nuestros muertos y desaparecidos. Por ello hay que leerlo, pues nos impele a comprender los hechos, a acomodar y a entender la historia para que no se repita, ipara que nunca más haya otro Ayotzinapa! ¡Para que nunca más desaparezca otra mujer! ¡Para que nunca más desaparezca una persona más!

\section{Referencia bibliográfica}

URIBE, Sara. (2012). Antígona González. Surplus ediciones. 